\title{
An Empirical Study on the Influencing Factors and Trade Potential of International Trade in African Regional Integration Organizations: A Case of ECOWAS and SADC
}

\section{Mariam Doumbouya and Liu Xia*}

Department of International Trade, Zhengzhou University, China

*Corresponding Author: Liu Xia, Professor, Department of International Trade, Zhengzhou University, China.
Received: July 01, 2021

Published: August 30, 2021

(C) All rights are reserved by Mariam

Doumbouya and Liu Xia.

\section{Abstract}

The success of countries and continents relies heavily on its capability to handle its trading activities as well as its policies regarding trading activities. The African continent, like the rest of the continents, still relies on trade for its successes and social-economic development. The aspect of regional integration of countries will come into play given that these trading activities take place within the country, between countries, and between the continents. The extra and intraregional organizations will be an influential factor when it comes to the success of the trade. The need to improve the overall stance of the African continent in the face of the world has forced the African leaders to come up with different regional organizations to aid in its economic activities. The article, therefore, covers on the factors influencing Africa's regional, potential bilateral trade whereby the econometric analysis methods are used in understanding the estimation model used in line with the OLS estimation and Random fixed effects. It also includes the significant factors behind the growth of exports, imports, and bilateral trade through engaging gravity variables as well as analysis of supplementary dummy variables. The findings of this article show that factors influencing international trade are economic components such as per capita GDP, difference exchange rate of currencies, GDP of involved countries as well as the distance between trading partners. The regional trading block on which the article focuses its studies on is the (ECOWAS SADC.

Keywords: International Trade; Empirical Potential Regional Trade; Africa Influential Factors; Gravity Mode

\section{Introduction}

African states have been working closely together over the years, and this dates back to the days when they were fighting for independence where by they supported each other in gaining their independence. The formation of independent governments led to the formation of regional blocks whose primary aim was to help each other across the divides of social, political, and economic development. The collaborations have, however, had their fair share of losses whereby the misunderstandings between member states have affected the performances of the regional organizations. According to Luthuli (2020), Regional integration allowed African countries to enhance their economic development and expansion strategies hence stabilizing the regional situation. The issues of political turbulence and monetary differentiation have been a challenge given that countries are not willing to create a common currency for the regional block. It, therefore, means that the monetary variation has negatively affected the success of regional trades given that there are minimal exchanges of goods and services as well as uniform growth of the members' state economies.

The economic integration means that the economic frontiers will be excluded across member states and regions trading partners, as stated by Bangura (2018). It also means that there will be mechanisms to improve the distance issues between the trading partners through the improvement of infrastructure, which will help in enhancing the facilitation of the movement of trading goods. African scholars and ideologists in this field have been working 
An Empirical Study on the Influencing Factors and Trade Potential of International Trade in African Regional Integration Organizations: A Case of ECOWAS and SADC

around the clock to unlock the entities which hinder the success of regional trading block. According to Amavilah, Asongu and Andrés (2017), the development of regional integration tends to focus on the economic aspects, which is unfortunately influenced by the political situation of the member countries. The success of the regional blocks will therefore depend on their willingness to handle the political situation of the member states in order to improve their economic integration. According to Eberhard-Ruiz and Moradi (2018) and Zouri (2019), increased intraregional trade leads to increased job creation and job opportunities because a properly integrated region is a recipe for faster economic growth.

\section{Materials and Methods}

The contents of this article were collected from various sources, with the primary focus being on the secondary sources. The choice of the source of information and data was down to its availability and timeliness, given that they are readily available in online and offline libraries. Using secondary sources is necessary for such undertakings, given that there was a limited timeframe for completing this work. Other sources apart from peer-reviewed journals were annual donor reports, academic studies, policy documents from the government of member states, NGOs, project documents, universities as well as information from private companies. The information targets the countries within SADC and ECOWAS, given that they are the two areas of studies in regards to their development and trade potentials (Barnekow and Kulkarni, 2017). The article does not have primary information and data from member states, but rather, it uses secondary data and information collected from the mentioned sources.

\section{Results and Discussion}

The external factors which affect the performance of these trading blocks are the influence of other trading blocks such as the European Union and other powerful countries such as China, the USA, and Japan. It is also worth noting that there are entities such as political situation among the nation and border issues that will significantly affect the trade performances and regional cohesion. The general conclusion based on the findings shows that the ECOWAS and SADC countries should ensure that they enhance their regional integration trade through bilateral trade growth among the member economies. The countries should also have a scheduled approach as well as a sequential approach meant to enhance their integration hence allowing the member states to abolish trade barriers. Afesorgbor (2017) argued that whereas the countries such as Morocco and South Africa have greatly benefited from the regional trades, it is still the international and world economies that influence their stability. The case presented means that the countries within other regional blocks such as European nations and their regional trade partnership will influence the growth rate of member states of the African regional trading block. Afesorgbor (2017) and Guan and Sheong (2020) also gave an example of China's economic growth and how their international activities in nations such as Africa have helped in enhancing their growth rate through its infrastructure development. The regional integration allows for the exploitation of the potential development of both the professional services exports and the private sector.

Education and regional trade

According to Bjornlund, Bjornlund and Van Rooyen (2020), the member states also acknowledge the effects and the need for the economies of education which include clear analysis between the international trade, academics realms, and their impact on the economy. A strong education system within member states will significantly improve the overall performances of the governments hence increasing their trade know-how (Czermińska and Garlińska-Bielawska, 2018). The education system of SADC member states has been applauded because of its capability to release graduates who easily slot into different sectors of employment, with trading sectors being beneficiaries. According to Tran et al. (2016), the Finnish government, for instance, has helped their regional trade through collaboration with the private sector and other stakeholders regarding their measures that can help them in improving their trading activities. It is through an education system that graduates can help the regional trading block to get a global perspective hence making it possible for them to improve their undertakings.

\section{Collaboration across regional blocks}

There is also the issue of collaboration between the member states and private sectors whereby they can bring them in to help in fostering flexibility and practicality regarding their business and economical maneuvers, which are necessary for regional trading. The approach will help in understanding the paradigm under which the trading activities can take so that they can hit their trading capabilities (Ambetsa, Mdadila, and Rutasitara, 2019; Iddrisu, 2018). The member states have been working towards improving their economic development and trading activities by working closely with their graduates towards sustainable solutions. According to Czermińska and Garlińska-Bielawska (2018), the key interesting factor with such an approach is that it gives a proper 
analysis of the global knowledge economy and trading opportunities. The member states should, therefore, eloquently apply their knowledge gained towards improving their influence as the regional trading block in international space (Verger, Fontdevila and Zancajo, 2016). The economic success of the regional block depends on its capability to transform trading knowledge into practical aspects in their trading endeavors.

Streamlining the education sector to match the dictates of trading aspects will give a better understanding and sustainable approach towards enhancing the dominance of the regional blocks in the international trading front, as discussed by Chakamera and Pisa (2020). ECOWAS and SADC need to understand that excellent trading knowledge is definitely necessary when carrying out economic and business endeavors with other trading blocks (Verger, Fontdevila and Zancajo, 2016; Heron and Murray-Evans, 2018). The aspect of privatization of the education sector can help the trading blocks in improving their political perspectives and its subsequent waves. The need to improve the dimension of these approaches is that they have brought about a much-needed impact to the leadership realm of the member states (Chakamera and Pisa, 2020). Trading standards and development success of the member states depend on the management approach used because they will influence how its leaders will transform such approaches. The interesting part of these trading aspects and regional trading partners is entrepreneurs influence the performances of their countries, given that they have the freedom to elect ideal leaders into leadership positions (Verger, Fontdevila and Zancajo, 2016). Public forums can also help in understanding the type of leaders that should be elected into the regional positions to enhance the success of their trading endeavors.

\section{Level of development in the member states}

Marlé van Eyk and Ferreira (2017), in their article regarding international trade, discussed how the sources of revenues differ across different nations because it is influenced by their level of development. The SADC and ECOWAS member states have been having difficulties when it comes to their contribution to the trade growth in the regional block because of their economic situations, as discussed by Heron and Murray-Evans (2018). Whereas the developing countries have witnessed a significant improvement in their trade and economic development, the continent of Africa is yet to realize its full potential. There have been approaches such as removing trade barriers as a way of mitigating the negative con- sequences that come with trading activities, as observed by Deme and Ndrianasy (2017). The move will also ensure that the country has better productivity and performances, which will, in turn, contribute to the improvement of regional trade and its underlying activities.

\section{Unleashing trading potential}

The current situation of the regional entities in African continents is that the major focus is the approach and measures that they will undertake in order to reduce the trading obstacles among the member countries (Ambetsa, Mdadila, and Rutasitara, 2019). In essence, the mentioned entity should not be a priority, but instead, the member countries should focus on approaches that they will use in enhancing the productivity of these regional blocks. Despite the importance of removing trade barriers and obstacles, it should not be given too much attention to the level where the regional blocks fail to reach their full potential (Deme and Ndrianasy, 2017). Southern African Development Community (SADC), for instance, should work on how they can enhance the productivity of the block rather than focusing on how they will remove the trade barriers in the region (Makochekanwa and Matchaya, 2019). Their rules and approaches should include aspects such as how the regional block will work with other blocks such as European Union towards enhancing their trade productivity.

According to Awad and Yussof (2017) and Malindisa (2017), there is a need for radical processes and trade aggressiveness among the African regional blocks because the continent has been lagging behind for so long that they are nearing the marginalization phase. They need to work together to improve their trading activities, their infrastructure as well as measures that will help in attracting more corporate into the regional block. The move will help in boosting the trading activities within these regions while also fostering trade aggressiveness which is necessary for the success of such undertakings.

\section{Challenges}

Hypothesis and experimental results that have been done by the scholars in the past do not have sufficient information regarding the priorities and plans that regional blocks in Africa have (Duong et al., 2019). It, therefore, shows that whereas the mechanisms to improve the trading activities in these regions are still in the balance, there is little that has been done to propel the realization of trade potential in these regional blocks. The other challenge which 
is yet to be addressed is the common currency or medium of exchange, whereby the current situation relies heavily on the foreign exchange currency and the economic stability of member countries (Diallo, Koivogui and Bah, 2018). The contribution of the member states, therefore, increases with the increase in their economy and currency, which means that they have to streamline their currency and economic stability to improve their contribution. African regional blocks like ECOWAS and SADC need to understand that they have to engage in the exchange of goods and services among member states in order to improve their stance in international trade (Afolabi, Aznin and Izraf, 2017). The said move is necessary as it plays a crucial role in the success of these country's economic developments.

According to Awad and Yussof (2017), comparative advantage theories show that the profitability of the bilateral trade within the regional blocks does not have an impact on other non-member states. It, therefore, means that the non-member states can strike bilateral deals with one of the member states so that they can work together as intra-trade partners. The scale of economics will therefore depend on the willingness of the cluster trading partners and the success of their trade partners in the regional trading blocks (Asante, 2018; Ngepah and Udeagha, 2018). For instance, if Ghana wants to gain from the establishment and trading success of SADC, she will have to strike an intra-trading partnership with a state like South Africa who is a member of SADC. Such cases mean that South Africa will be able to bring Ghana's commodities into this regional block as long as it is within the scales set by the trading block [118].

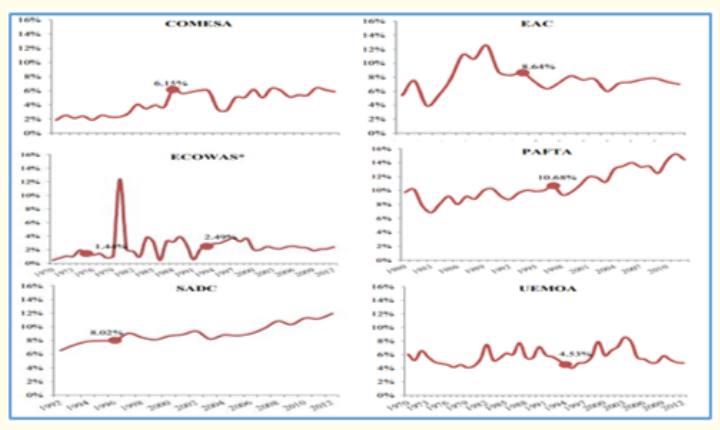

Figure 1: Total imports growth share into intra-regions Gumede, Oloruntoba and Kamga (2020).

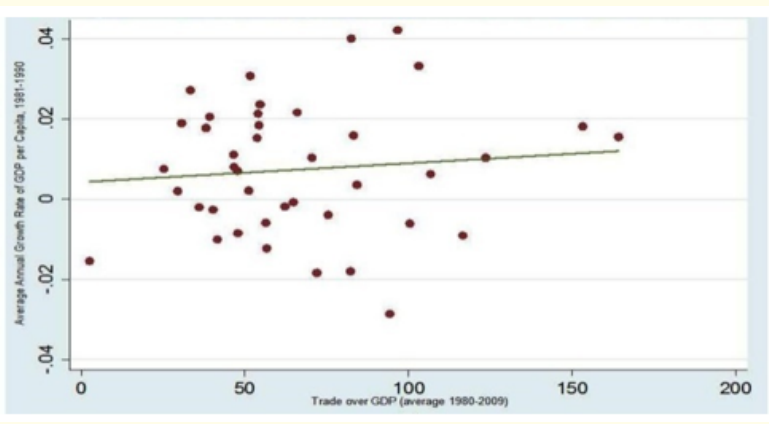

Figure 2: Growing faster more open to trade sub-Saharan-Africa 1981-2009 Takele (2019).

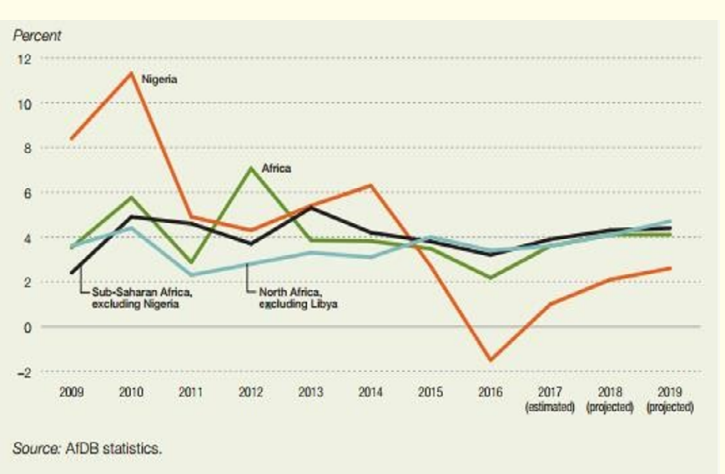

Figure 3: Africa Real GDP growth, 2009- 2019.

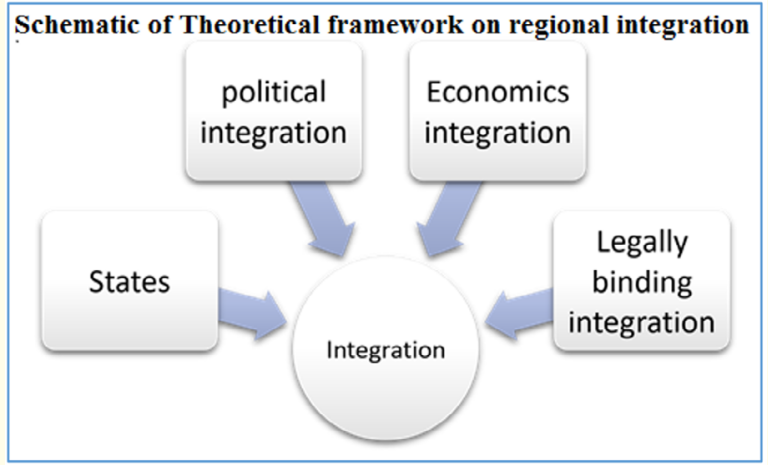

Figure 4: Schematic of Theoretical framework on regional integration, (Sunge and Ngepah, 2020). 


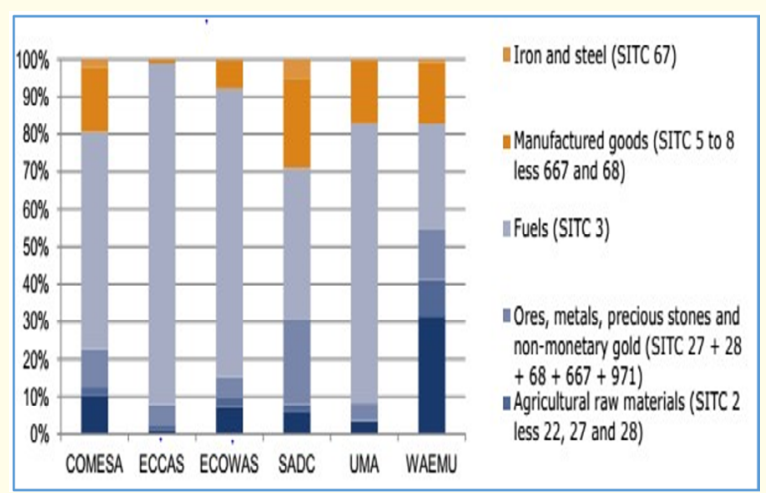

Figure 5: Top Potential products exports by regional countries

(Songwe, 2019).

\section{Conclusion}

If countries have a standard trading block in place, outside countries or regional blocks will use them as a case study and even strike a trading partnership deal with them hence improving the overall stance of international trade. There are sufficient resources in Africa, but with the little exploitations of these resources, their impact on the international stage has not been impressive.

It is also imperative to note that educations matters, and the timing of graduate cohorts influence their absorption index into their workplace, and this concept can also be used in the recruitment of graduates into various sectors within the regional block. The economy and success of ECOWAS depend on the expertise released into the field, but their level of academics and capability to put their knowledge into real-world scenarios has been composite to their employability. The research also shows that the investment made to the education sector by individual states leads to improved trading and economic performances. Proper management and realization of the potential of African regional trade integration will foster their economic development both as individual countries and as a block. Therefore, trade liberalization will play a significant role in the success of regional trades in line with their international scale.

\section{Recommendation}

Given that there was little timeframe to carry out comprehensive research on this subject matter, the information provided and the analysis of the situation are not explicit. It is for this case that the other researchers will have to focus on the research gap that ex- ists in this particular paper. The first recommendation that needs to be factored in is the issue of governance policies and structures. In this case, the regional blocks will have to formulate a central government structure that will guide the development of trading activities within the region. The unit should be clustered as an independent body that will not crumble under the pressure of member states. The policies should also be included in this category to incorporate the measures that will be undertaken in case the member states fail to meet the set requirements. It is also necessary to focus on ways that will help the governments of the member states to improve their policies that will favor the overall development of the trading activities within the regional blocks.

Given that the international countries are still venturing into Africa for trading activities and other donor deals, the regional governments will have to structure a framework under which they will be working with their international trading partners. For instance, if the Chinese government will want to venture into one of the member states to help them in their trading activities, the regional block will have to be notified. The approach will help them in evaluating and analyzing the situation so that the end results will be favoring both the regional and the specific member state. It will also help in promoting the regional block such that if the international country, say China, is coming in to help in developing infrastructures, the other nations will benefiting from such developments given that trade relies heavily on infrastructure. The use of information technology in the regional management of trading activities will also help in improving efficiency and enhancing transparency in their dealings. It is, therefore, necessary to ensure that there are continued activities within the region on how the member states will fasten their technology advancements in their states. It will also be necessary to carry out research to determine the trading components that are demand-driven, practical as well as relevant to the overall development of trading in the region. It will also be necessary to improve the policies regarding business activities such as supply and demand of goods. The regional trading block should give each other first priority when it comes to the purchase of goods and services and sell their excesses outside their regional block whenever possible. Lastly, there is still a long way to go when it comes to culture and management capacities in the region. The governing bodies in the regional blocks should improve the cultural situation of the member states as well as their language aspects to improve their overall collaboration. 


\section{Acknowledgement}

We would like to express our gratitude towards previous researchers and method managers, who have examined upon the problems of sustainable business, Human relations practices and feasibility. Without their support, we could not have written this paper.

\section{Conflict of Interest}

No any conflict of interest exists.

\section{Bibliography}

1. S Chen., et al. "A clustering technique for digital communications channel equalization using radial basis function networks". IEEE Transactions on Neural Networks and Learning Systems 4 (1993): 570-578.

2. J U Duncombe. "Infrared navigation-Part I: An assessment of feasibility". IEEE Transactions on Electron Devices ED-11 (1959): 34-39.

3. C Y Lin., et al. "Rotation, scale, and translation resilient public watermarking for images". IEEE Transactions on Image Processing 10.5 (2001): 767-782.

4. A Cichocki and R Unbehaven. "Neural Networks for Optimization and Signal Processing". 1st ed. Chichester, U.K. Wiley 2 (1993): 45-47.

5. WK Chen. "Linear Networks and Systems". Belmont, CA: Wadsworth (1993): 123-135.

6. H Poor. "An Introduction to Signal Detection and Estimation". New York: Springer-Verlag (1985): 4.

7. RA Scholtz. "The Spread Spectrum Concept". In Multiple Access, N. Abramson, Ed. Piscataway, NJ: IEEE Press 3 (1993): 121-123.

8. GO Young. "Synthetic structure of industrial plastics". in Plastics, 2nd ed. J. Peters, Ed. New York: McGraw-Hill 3 (1964): 1564.

9. MB Kasmani. "A Socio-linguistic Study of Vowel Harmony in Persian (Different Age Groups Use of Vowel Harmony Perspective". International Proceedings of Economics Development and Research, ed. Chen Dan (2011): 359-366.

10. W D Doyle. "Magnetization reversal in films with biaxial anisotropy". in Proc. 1987 INTERMAG Conf., (1987): 2.2-1-2.2-6.
11. G W Juette and L E Zeffanella. "Radio noise currents n short sections on bundle conductors". presented at the IEEE Summer Power Meeting, Dallas, TX, June 22-27 (1990).

12. J Williams, "Narrow-band analyzer". Ph.D. dissertation, Dept. Elect. Eng., Harvard Univ., Cambridge, MA, 1993.

13. N Kawasaki. "Parametric study of thermal and chemical nonequilibrium nozzle flow". M.S. thesis, Dept. Electron. Eng., Osaka Univ., Osaka, Japan (1993).

14. J P Wilkinson. "Nonlinear resonant circuit devices". U.S. Patent 3624 12, July 16 (1990).

15. Letter Symbols for Quantities, ANSI Standard Y10.5-1968.

16. Transmission Systems for Communications. 3rd ed., Western Electric Co., Winston-Salem, NC (1985): 44-60.

17. Motorola Semiconductor Data Manual, Motorola Semiconductor Products Inc., Phoenix, AZ (1989).

18. R J Vidmar. "On the use of atmospheric plasmas as electromagnetic reflectors". IEEE Transactions on Plasma Science 21.3 (1992): 876-880.

\section{Volume 5 Issue 9 September 2021}

(C) All rights are reserved by Mariam Doumbouya and Liu Xia.

.

\section{.}

